\title{
Recurrent Ectopic Pregnancy in Distal Remaining Portion of Fallopian Tube Following Proximal Ipsilateral Salpingectomy
}

\author{
Katewa $\mathrm{S}^{1 *}$, Sarkar $\mathrm{S}^{2}$, Meitei LT ${ }^{3}$ and Chowdhury $\mathrm{P}^{2}$ \\ ${ }^{1}$ Senior Resident, Department of Obstetrics \& Gynecology, Dr. S.N.Medical College, \\ Jodhpur (Rajasthan), India \\ 2Ex- Post-Graduate Trainee, Department of Obstetrics \& Gynaecology, RIMS Imphal \\ (Manipur), India \\ ${ }^{3}$ Registrar, Department of Obstetrics \& Gynaecology, RIMS Imphal (Manipur), India
}

\section{Case Report}

Volume 3 Issue 1

Received Date: April 06, 2018

Published Date: April 28, 2018

*Corresponding author: Dr. Suman Katewa, Senior Resident, Dr. S.N.Medical College Jodhpur, 11/981 CHB Jodhpur, Rajasthan, India, Tel: 9772977935; Email: drsumankatewa@gmail.com

\begin{abstract}
Ectopic pregnancy is defined as a pregnancy that implants outside the uterine cavity. Its reported incidence is $1-2 \%$ of total pregnancies. However the female with a previous ectopic pregnancy has a fourfold chance of recurrent ectopic pregnancy but recurrence of ectopic pregnancy in distal remaining portion of fallopian tube after ipsilateral proximal salpingectomy is extremely rare. Due to its rarity here we present a case of ectopic pregnancy occurring in distal remaining portion of fallopian tube after proximal ipsilateral salpingectomy.

Keywords: Pregnancy; Abdomen; Ipsilateral Proximal Salpingectomy; Fallopian Tube
\end{abstract}

\section{Introduction}

Ectopic nidation of a fertilized ovum is invariably fatal to the foetus and often to the mother. Early diagnosis of ectopic pregnancy is of paramount importance as ectopic pregnancy is still the commonest cause of first trimester maternal death, accounting for around $73 \%$ early pregnancy related maternal death [1]. Rate of ectopic pregnancy detection has recently increased due to in vitro fertilization, embryo transfer, microsurgical techniques, and better early diagnosis [2]. History of pelvic inflammatory disease has been implicated as a causative factor for ectopic pregnancy. Recurrence of ectopic pregnancy who have had an ectopic pregnancy is high (8$17 \%)$, but ipsilateral ectopic pregnancy following partial or total salpingectomy is rare as very few cases have been reported in literature. As maternal mortality rate is 10 $15 \%$ higher in such type of ectopic pregnancy so high index of suspicion is must for early diagnosis and early interventions.

\section{Case Report}

A 32-years-old Manipuri female, G3P1011, presented with a history of six weeks of amenorrhea, nausea, and severe abdominal pain of two days duration with mild bleeding per vagina for 1 day. Her past medical records revealed that she had undergone right-sided proximal partial salpingectomy for ectopic pregnancy 4 years back which was later on confirmed by histopathological report. 
Physical examination revealed moderate pallor, abdominal guarding and rebound tenderness, pulse rate of 120 beats/min and blood pressure of $90 / 50 \mathrm{mmHg}$. The pelvic examination revealed a bulky multiparous, antiverted uterus with closed OS and right forniceal mass $4 \times 4 \mathrm{~cm}$ in dimension. Cervical motion tenderness was present. Urine pregnancy test was positive and quantitative human chorionic gonadotropin (ß-HCG) estimation was 3200 IU/L. Emergency resuscitation measures were taken by starting 2 intravenous lines with crystalloid. Hematological investigation revealed 6.5 $\mathrm{gm} / \mathrm{dl}$ hemoglobin. Cross matching for 2 units of packed RBC was sent. Emergency ultrasonography was done to confirm the diagnosis. USG showed empty uterine sac and right adenexal mass of $4 \times 3 \mathrm{~cm}$ with free fluid in pouch of Douglas. In view of past history of ectopic pregnancy and current features suggestive of ruptured ectopic pregnancy, the decision was taken for urgent laparotomy. Around $500 \mathrm{ml}$ blood was removed from peritoneal cavity. Right sided ruptured ectopic tubal mass measuring $4 \mathrm{x} 3$ $\mathrm{cm}$ was identified in the distal portion of the tube. Proximal end of right fallopian tube was absent which reconfirmed the previous right sided proximal partial salpingectomy. Right ovary and left tube with ovary was normal. Some adhesions were present between the tubal mass and bowel loop. The tubal mass was dissected from the bowel loops and the remaining distal portion of the right fallopian tube was removed. Hemostasis was achieved and after proper peritoneal toileting the abdomen was closed in layers. Patient received 3 unit of PRBC. Her post operative course was uneventful and was discharged on $6^{\text {th }}$ post operative day. Histopathological report confirmed ruptured tubal gestation (Figure 1).

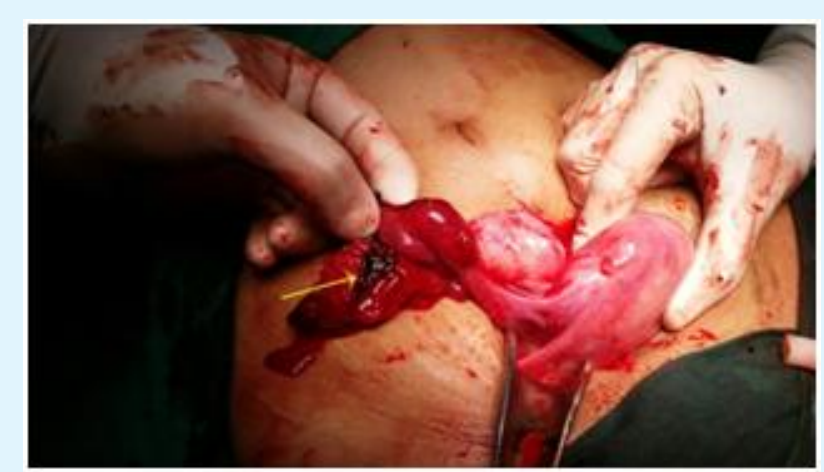

Figure 1: Ectopic pregnancy in distal portion of fallopian tube.

\section{Discussion}

Due to its varied clinical presentation ranging from asymptomatic cases to haemoperitoneum and shock, ectopic pregnancy can masquerade many gynaecological and non-gynaecological conditions. The classic triad of amenorrhoea, abdominal pain and vaginal bleeding is present in only $50 \%$ of the patients with ectopic pregnancy [3]. The incidence of recurrent ectopic pregnancy is approximately $15 \%$ and this rises to $30 \%$ following two ectopic pregnancies [4]. Any woman with a previous history of ectopic pregnancy is high risk for recurrent ectopic so high risk of suspicion should be kept. Recurrent ectopic pregnancy occurring in the proximal remaining stump of the tube following ipsilateral distal salpingectomy has been reported before $[5,6]$. Sangal and Kotwal [7] reported an unusual presentation of a third tubal pregnancy associated with the fimbrial end of a previous right partial salpingectomy and left tubal salpingectomy. Concomitant bilateral tubal ectopic pregnancies after bilateral partial salpingectomy for sterilization have also been reported [8]. The use of endo loop ligation for the surgical treatment of ectopic pregnancy has been considered to result in ipsilateral ectopic pregnancy in the remaining tubal stump [9].

Present case is unique in the fact that the recurrence of ectopic pregnancy occurred in the distal remaining segment of the fallopian tube after ipsilateral proximal salpingectomy. Recurrent ectopic pregnancy in the distal remaining end of a fallopian tube following ipsilateral proximal salpingectomy is extremely rare. After extensive search of literature we could find only less than 5 such reported cases $[10,11]$. The answer to the question "how the ectopic did get there" is not clear. There are three possible postulations that can answer the question (Figure 2). First is that Spermatozoa passed through the left patent tube into the pouch of Douglas and traveled to fertilise the ovum on the distal remnant portion of right fallopian tube [12]. Second possibility is that, lumina persisted in the interstitial portion and distal remnant of the right fallopian tube or recanalisation may have occurred allowing communication between the endometrial and peritoneal cavities and thus migration of spermatozoa or the fertilised egg from the endometrial cavity to the distal remnant of the right fallopian [10]. Third extremely rare possibility is of transperitoneal embryo migration [13]. 


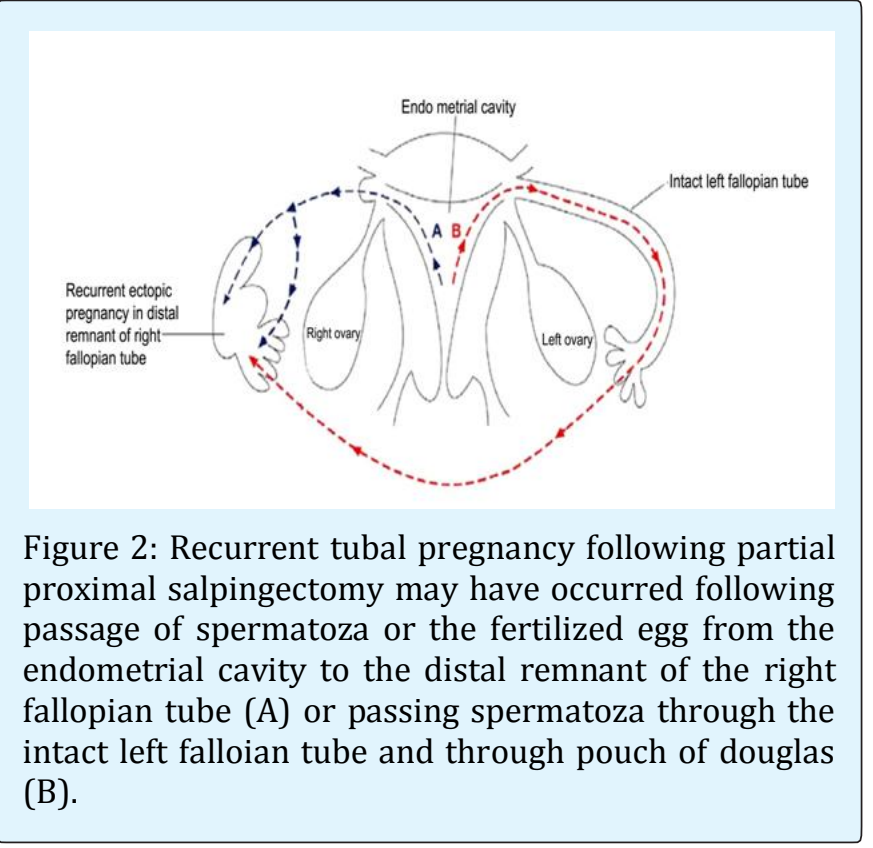

Given the uncertain nature of the mechanism for ipsilateral ectopic in tubal remnant, selecting a method for prevention is quite difficult. However taking care of few things may help in decreasing the incidence like tubal stump should be kept of minimal length while performing salpingectomy. Beside this complete peritonisation of the corneal incision and advancement of the round and broad ligament over the uterine cornua (modified Coffey technique) and cauterization of the remaining stump may have promising role [14].

\section{Conclusion}

Thus salpingectomy as a treatment modality for ectopic pregnancy does not exclude recurrence of epsilateral tubal ectopic. Clinician should be aware about the fact that one ectopic increases the risk of further ectopics. In the present era where the preservation of tube while managing the tubal pregnancy is strongly advocated, the risk of recurrent ectopic in ipsilateral tube should be anticipated and whenever such recurrent cases are seen, they should be managed vigorously to prevent maternal morbidity and mortality. Beside these Women with a history of ectopic pregnancy should have early ultrasonography to verify a viable intrauterine pregnancy in their subsequent pregnancies.

\section{References}

1. Condous G (2006) Ectopic pregnancy-risk factors and diagnosis. Aust Fam Physician 35(11): 854-857.

2. Dialanini V, Levine D (2004) Ectopic pregnancy: a review. Ultrasound Q 20(3): 105-117.

3. Stovall TG (2002) Early pregnancy loss and ectopic pregnancy. In: Berek JS (Ed.), Novak's Gynecology, Lippincott Williams \& Wilkins, Philadelphia, pp: 507-542.

4. Tulandi $\mathrm{T}$ (1988) Reproductive performance of women after two tubal ectopic pregnancies. Fertil steril 50(1): 164-166.

5. Tabandeh A, Besharat M (2012) Recurrent ectopic pregnancy in the fallopian tubes. J Clin Diag Research 6(3): 493-494.

6. Samiei-Sarir B, Diehm C (2013) Recurrent ectopic pregnancy in the tubal remnant after salpingectomy. Case Rep Obstet Gynecol 2013: 753269.

7. Sangal PR, Kotwal H (1987) Unusual presentation of a third tubal pregnancy: a case report. J Reprod Med 32: 320-321.

8. Adair CD, Benrubi QI, Sanchez-Ramos L, Rhatgan R (1994) Bilateral tubal ectopic pregnancies after bilateral partial salpingectomy: a case report. J Reprod Med 39(2): 131-133.

9. Fischer S, Keirse MJ (2009) When salpingectomy is not salpingectomy- ipsilateral recurrence of tubal pregnancy. Obstet Gynecol Int 2009: 524864.

10. Zuzarte R, Khong CC (2005) Recurrent ectopic pregnancy following ipsilateral partial salpingectomy. Singapore Med J 46(9): 476-478.

11. Al-Inizi (2015) Recurrent Ectopic Pregnancy Following Ipsilateral Proximal Salpingectomy. J Clin Gynecol Obstet 4(1): 188-190.

12. Yano T, Ishida H, Kinoshita T (2009) Spontaneous ectopic pregnancy occurring in the remnant tube after ipsilateral salpingectomy: a report of 2 cases. Reproductive Medicine and Biology 8(4): 177-179. 


\section{Open Access Journal of Gynecology}

13. Fruscella L, Danti M, Toti R (1994) Extrauterine pregnancy in residual tube stump in a patient already treated with partial salpingectomy for right ampullar pregnancy. Report of a clinical case. Minerva Ginecol 46(12): 695-697.
14. Rock JA, Jones HW III (2008) Ectopic pregnancy. Te Linde's Operative gynaecology, $10^{\text {th }}$ (Edn.), Wolters Kluwer, Lippincott Williams \& Wilkins, pp: 813. 